\title{
Beryllium exposure and pulmonary function: a cross sectional study of beryllium workers
}

\author{
D KRIEBEL,' NANCY L SPRINCE, ${ }^{3}$ ELLEN A EISEN, ' I A GREAVES,' \\ H A FELDMAN, ${ }^{2}$ R E GREENE
}

From the Occupational Health Program, ${ }^{1}$ and Respiratory Biology Program, ${ }^{2}$ Harvard School of Public Health, the Department of Medicine (Pulmonary Unit), ${ }^{3}$ Massachusetts General Hospital and Harvard Medical School, and Department of Radiology, ${ }^{4}$ Massachusetts General Hospital, Boston MA 02115, USA

ABSTRACT A cross sectional study of 297 white male workers employed in a large beryllium plant was conducted to test the hypothesis that long term exposure to beryllium is associated with decrements in pulmonary function. Spirometric measurement of pulmonary function, chest radiographs, and arterial blood gas measurements were collected. After controlling for age, height, and smoking in multivariate regression models, decrements in FVC and FEV, were found to be associated with cumulative exposure to beryllium in the period up until 20 years before the health survey. These decrements were observed in workers who had no radiographic abnormalities. The alveolar-arterial oxygen difference was associated with cumulative exposure in the 10 years immediately before survey, after controlling for age and smoking. These findings suggest that beryllium may have both short and long term pulmonary effects that are distinct from the classic forms of acute and chronic beryllium disease.

Beryllium disease of the lung is a potentially disabling granulomatous disorder caused by inhaling beryllium compounds.' Much of the research on the health effects of beryllium has focused on the chronic form of the disease, which is generally progressive, often disabling, and is characterised by pronounced radiographic changes and functional impairments in the lungs. Less well understood are the subclinical effects of beryllium and the relation between exposure to beryllium and the degree of lung dysfunction. Such studies require medical monitoring of a large group of workers exposed to estimable levels of the metal for long periods but this has seldom been done. ${ }^{2-4}$ In one group of workers an early, reversible condition was described and characterised by mild hypoxaemia, increased alveolar-artcrial oxygen gradient, and mild interstitial infiltrates. ${ }^{23}$ A similar effect has been observed experimentally in dogs.

We describe the changes in lung function and the radiographic changes in workers at a large beryllium extraction and manufacturing plant who have been under study by one of us (NS) since 1977. Elsewhere we have provided estimates of exposure to beryllium in

Accepted 9 February 1987 the plant. ${ }^{6}$ We describe results of a cross sectional examination of this group using the health effects data obtained in 1977.

The availability of medical monitoring data and historical industrial hygiene surveys at this large beryllium plant enabled us to test the hypothesis that long term exposure to beryllium was associated with decrements in pulmonary function and interstitial changes seen on chest radiographs and to assess the modifying effects of such factors as the timing and intensity of the exposure.

\section{Methods}

EXPOSURE ASSESSMENT

A preceding paper detailed the estimation of beryllium exposure histories for each worker in the cohort and the development of exposure parameters. ${ }^{6}$

\section{MEASUREMENT OF HEALTH \\ EFFECTS}

Spirometry-Lung spirometry was performed on each subject while seated using a heated Fleisch No 3 pneumotachograph (Hewlett Packard). Measurements were obtained for forced vital capacity (FVC) forced expiratory volume in one second 
$\left(F E V_{1}\right)$, and maximum mid-expiratory flow (MMEF). For FVC and $\mathrm{FEV}_{1}$, the maximum value of three acceptable blows (without regard to the variance of the measurements) was used, even if the selected FVC and $\mathrm{FEV}_{1}$ values came from separate blows. ${ }^{7}$ The MMEF was obtained from the blow with the largest sum of $\mathrm{FVC}$ and $\mathrm{FEV}_{1}$. Standing height was measured in inches without shoes.

Chest radiographs-Posteroanterior chest radiographs were taken on each worker and read by a certified B-reader using the current ILO system for reading and coding pneumoconioses. ${ }^{8}$

Blood gases-Arterial blood gases were determined for each worker while at rest. With the subject seated and breathing room air, blood was collected from the radial artery into heparinised syringes and analysed immediately at $37^{\circ} \mathrm{C}$ for $\mathrm{PaO}_{2}, \mathrm{PaCO}_{2}$, and pH (Instrumentation Laboratories, model 213, Boston, MA). The alveolar-arterial oxygen gradient $\left(\mathrm{AaDO}_{2}\right)$ was calculated using the ideal alveolar air equation. ${ }^{9}$

Questionnaire-The British Medical Research Council questionnaire was administered to collect information on respiratory symptoms and smoking; additional data were collected from job histories. Pack-years of smoking were calculated as the product of the number of years of smoking and the average number of packs a day of cigarettes consumed.

\section{STATISTICAL METHODS}

In a preliminary analysis the $\mathrm{FVC}$ and $\mathrm{FEV}_{1}$ values for white men were compared with data from a large standard population ${ }^{10}$ : per cent predicted values were calculated using predicted values based on age and height. The average total cumulative exposure was compared for those workers in the lowest decile of function with those in the upper $50 \%$ of the distribution, after adjusting for age, height, and smoking.

Conditional associations between outcome variables and exposure parameters were assessed using multivariate models. Least squares regression was used for continuous dependent variables; logistic regression was used for dichotomous outcomes. Both linear and logistic models are shown in a linear form; it should be noted that when a dichotomous outcome variable is referred to, the dependent variable is not $y$ but the logit of the probability of the dichotomous outcome - that is, $\ln [\mathrm{p} / 1-\mathrm{p}]$.

Variables assumed a priori to be effect modifiers (age and height for FVC, FEV, MMEF; age for $\mathrm{AaDO}_{2}$, and radiographic abnormalities) were included in all models, regardless of the magnitudes of their effects or the results of statistical tests. Quadratic forms for the age and height variables changed neither the overall fit of the models nor the magnitudes of exposure effect estimates, hence the simple linear forms are reported. The possibility of a different effect of smoking among ex-smokers was accounted for by creating two pack-year variables, one for current smokers and one for ex-smokers. Never smokers and smokers of pipes and cigars were assigned zero for both pack-year terms. Smoking exposure interactions were investigated with product terms: smoker (yes/no) $\times$ exposure, pack-years $\times$ exposure.

Regression cocfficients (b values) were used to characterise the magnitude of effects and the respective standard errors were used to assess the precision of the estimates. Significance levels of $b$ values were determined from $F$ tests of the null hypothesis that an individual $b$ was equal to zero. When a set of exposure variables was assessed - for example, exposures occurring in three different periods - an effect estimate was termed "conditional" when the other exposure parameters of the set were included in the model and "unconditional" when they were not. A serics of sensitivity analyses were performed to investigate the robustness of the main findings. These consisted of fitting exposure response models in which the cxposure parameters were expressed in different mathematical forms and in which exposure terms were fitted both unconditionally and conditionally on other exposure parameters.

\section{Results}

The total production workforce in 1977 consisted of 350 workers, of whom 309 were studied. Measurements were obtained from 297 white men who represented $85 \%$ of the workforce. This group had an average age of 43 and had worked on average 17 years in the plant (table 1): $44 \%$ had worked more than 20

Table 1 Summary statistics of study population of 297 white men

\begin{tabular}{|c|c|c|c|}
\hline & Mean & Median & $S D^{*}$ \\
\hline Age (years) & $43 \cdot 2$ & $44 \cdot 0$ & $11 \cdot 0$ \\
\hline Years employed & $17 \cdot 1$ & $17 \cdot 0$ & $10 \cdot 3$ \\
\hline Height (inches) & $68 \cdot 8$ & $69 \cdot 0$ & $2 \cdot 4$ \\
\hline \multicolumn{4}{|l|}{ Smoking status: } \\
\hline Current & $48 \%$ & & \\
\hline Ex-smoker & $24 \%$ & & \\
\hline Never smoker & $22 \%$ & & \\
\hline Pipe/cigar & $6 \%$ & & \\
\hline Pack-years of cigarettest & $32 \cdot 0$ & $26 \cdot 0$ & $25 \cdot 3$ \\
\hline \multicolumn{4}{|l|}{ Pulmonary function: } \\
\hline FVC (1) & 4.69 & $4 \cdot 77$ & 0.85 \\
\hline $\mathrm{FEV}_{1}(1)$ & 3.44 & 3.48 & 0.76 \\
\hline MMEF (I) & $3 \cdot 10$ & 3.09 & $1 \cdot 26$ \\
\hline $\mathrm{AaDO}_{2}(\mathrm{~mm} \mathrm{Hg})$ & 11.6 & $11 \cdot 2$ & $10 \cdot 0$ \\
\hline \multicolumn{4}{|l|}{ Profusion of small and } \\
\hline $\begin{array}{l}-0.0 / 0 \\
-0.00\end{array}$ & $91 \%$ & & \\
\hline $0 / 1$ & $1 \%$ & & \\
\hline $1 / 0.1 / 1$ & $7 \%$ & & \\
\hline $1 / 2$ and greater & $1 \%$ & & \\
\hline
\end{tabular}

*Standard deviation.

tFor current and ex-smokers. 
years and $17 \%$ for less than five years. About half the cohort were current smokers.

The substantial majority of chest radiographs were normal. A total of 28 subjects $(9 \%)$ had profusions of small or irregular opacities with a score of $0 / 1$ or greater. For analysis, these data were collapsed into the presence or absence of profusions of $0 / 1$ or greater. Large opacities and pleural changes were rare and these data were not analysed.

For both current smokers and never-smokers, FVC was slightly higher than predicted by the equations of Dockery et $a l^{10}$ which were used to adjust for differences in age, height, and amount of smoking (table 2). Mean FEV , was lower than predicted, particularly in never smokers.

As a first step in examining exposure response relation, members of the cohort were identified who represented the "worst" decile for a particular outcome measure, after adjusting for age, height, and smoking. Those in the lowest decile for FVC and $\mathrm{FEV}_{1}$ had higher exposure levels and had worked longer than had the comparison groups, although $t$ tests of the differences in the geometric means were not significant at $p=0.05$ (table 3). A similar result occurred when those workers with high values of $\mathrm{AaDo}_{2}$ were compared with subjects who had a normal $\mathrm{AaDO}_{2}$. By contrast, similar exposure estimates were found when adjusted MMEF levels were used (table 3).

Several multivariate models were examined that included terms for exposure and for the effect modifiers and smoking. The simplest models included either total cumulative exposure, years worked, or both terms as continuous variables (tables 4 and 5). Age, height, and smoking terms behaved as expected. The exposure coefficients were of the correct sign to indicate an exposure effect but the magnitudes of
Table 2 Forced vital capacity (FVC) and forced expiratory volume in one second $\left(F E V_{1}\right)$ : crude and predicted values for never-smokers and current smokers*

\begin{tabular}{|c|c|c|c|c|c|}
\hline & \multirow[b]{2}{*}{ No } & \multicolumn{2}{|l|}{ Litres } & \multicolumn{2}{|c|}{$\%$ predicted } \\
\hline & & Mean & $S D$ & Mean & $S D$ \\
\hline \multicolumn{6}{|c|}{ Never-smokers: } \\
\hline FVC & 63 & $4 \cdot 82$ & $0 \cdot 79$ & 102 & 13 \\
\hline FEV & 63 & $3 \cdot 62$ & 0.70 & 95 & 15 \\
\hline \multicolumn{6}{|c|}{ Current smokers: } \\
\hline FVC & 141 & $4 \cdot 71$ & $0 \cdot 88$ & 105 & 14 \\
\hline $\mathrm{FEV}_{1}$ & 141 & 3.40 & 0.85 & 98 & 17 \\
\hline
\end{tabular}

*Predicted values obtained from equations of Dockery et al. ${ }^{10}$

association were generally small and statistically unstable. Only in models for $\mathrm{AaDO}_{2}$ were these exposure parameters important predictors of outcome. Models that used categorical codings for cumulative exposure or years worked gave similar results.

Exposure response models were constructed which allowed for differences in the strength of the association between health effects and cumulative exposures that occurred during different periods. Three exposure parameters, $\mathrm{CE}_{1-10}, \mathrm{CE}_{11-20}$, and $\mathrm{CE}_{\geqslant 21}$ were used and are described in the previous paper ${ }^{6}$; these represent the sum of exposure to beryllium received in the three periods 1 to 10,11 to 20 , and more than 20 years before the health survey, respectively. This exposure response model was given by:

$$
\begin{gathered}
y=b_{0}+b_{1} \text { age }+b_{2} \text { height }+b_{3} \text { current pack-years } \\
+b_{4} \text { ex-pack-years }+b_{5} C E_{1-10}+b_{6} C E_{11-20}+b_{7} \\
C E_{\geqslant 21}
\end{gathered}
$$

Both FVC and FEV, were associated strongly and negatively with exposures in the distant past (more

\begin{tabular}{|c|c|c|c|c|c|c|c|c|c|}
\hline & \multirow[b]{2}{*}{ No } & \multicolumn{4}{|c|}{ Cumulative exposure $\left(\mu \mathrm{g} / \mathrm{m}^{3}-\right.$ years $)$} & \multicolumn{4}{|c|}{ Duration of employment (years) } \\
\hline & & $\begin{array}{l}\text { Geometric } \\
\text { Mean }\end{array}$ & $S D$ & $p$ & Median & $\begin{array}{l}\text { Arithmetic } \\
\text { Mean }\end{array}$ & $S D$ & $p$ & Median \\
\hline \multicolumn{10}{|l|}{ FVC: } \\
\hline $\begin{array}{l}\text { Lowest } 10 \% \\
\text { Highest } 50 \%\end{array}$ & $\begin{array}{r}29 \\
149\end{array}$ & $\begin{array}{l}56 \\
30\end{array}$ & $\begin{array}{r}11.0 \\
9.7\end{array}$ & $0 \cdot 18$ & $\begin{array}{r}140 \\
65\end{array}$ & $\begin{array}{l}19 \\
16\end{array}$ & $\begin{array}{r}9.8 \\
11.0\end{array}$ & $0 \cdot 12$ & $\begin{array}{l}23 \\
16\end{array}$ \\
\hline \multicolumn{10}{|l|}{ FEV: } \\
\hline $\begin{array}{l}\text { Lowest } 10 \% \\
\text { Highest } 50 \%\end{array}$ & $\begin{array}{r}29 \\
149\end{array}$ & $\begin{array}{l}46 \\
32\end{array}$ & $\begin{array}{r}11 \cdot 0 \\
9.8\end{array}$ & 0.45 & $\begin{array}{l}66 \\
46\end{array}$ & $\begin{array}{l}19 \\
16\end{array}$ & $\begin{array}{l}10 \cdot 0 \\
11.0\end{array}$ & $0 \cdot 27$ & $\begin{array}{l}23 \\
13\end{array}$ \\
\hline \multicolumn{10}{|l|}{$\begin{array}{l}\text { Highest } 50 \% \\
\text { MMEF: }\end{array}$} \\
\hline Lowest $10 \%$ & 27 & 37 & $9 \cdot 7$ & & 47 & 17 & 11.0 & & 12 \\
\hline $\begin{array}{l}\text { Highest } 50 \% \\
\text { AaDO : }\end{array}$ & 131 & 33 & $10 \cdot 0$ & $0 \cdot 82$ & 45 & 16 & $10 \cdot 0$ & $0 \cdot 87$ & 14 \\
\hline $\begin{array}{l}\text { Aaw } \\
\text { Highest } 10 \%\end{array}$ & 29 & 63 & $9 \cdot 3$ & & & 18 & $9 \cdot 3$ & & 21 \\
\hline Lowest $50 \%$ & 149 & 35 & $10 \cdot 0$ & $0 \cdot 21$ & 63 & 19 & $10 \cdot 0$ & 0.64 & 19 \\
\hline Full cohort & 297 & 39 & 9.8 & & 65 & 17 & 10.0 & & 18 \\
\hline
\end{tabular}

Table 3 Comparison of cumulative exposure and duration of exposure for the lowest decile and upper 50\% of the population on adjusted measures of pulmonary function 
Table 4 Models for three measures of pulmonary function using the exposure variables total cumulative exposure and number of years worked. Regression parameter \pm standard error ( $p$ value*)

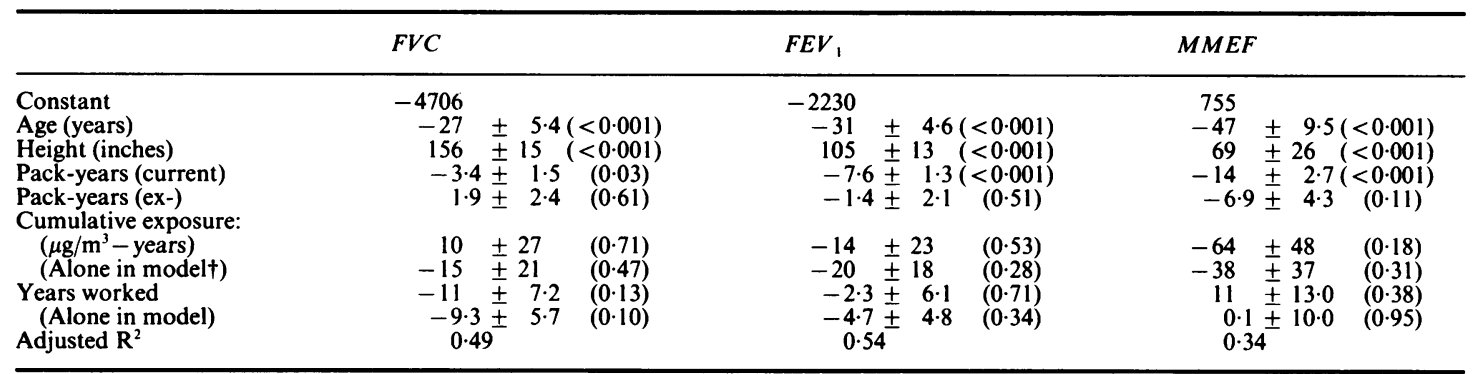

*From one df $\mathrm{F}$ test of $\mathrm{H}_{0}: \mathrm{b}=0$.

tIn a model with all the terms shown, except the years worked term.

than 20 years before the health survey) and were associated weakly with more recent exposures (tables 6 and 7). The MMEF was not associated with past or recent exposures. A positive association was observed between $\mathrm{AaDO}_{2}$ and recent exposure but past exposures showed no association. Radiographic abnormalities were associated weakly with recent exposures (tables 6 and 7). No evidence was found for an interaction between smoking and any of the parameters of beryllium exposure.

These analyses were repeated with each of the exposure effects estimated unconditionally-that is, from models that included effect modifiers and smoking but no other exposure parameter. The unconditional results agreed closely with those in tables 6 and 7.

The periods for partitioning cumulative exposure

Table 5 Models for alveolar-arterial oxygen gradient $\left(\mathrm{AaDO}_{2}\right)$ and the profusion of small and irregular radiographic opacities, using the exposure variables total cumulative exposure and number of years worked. Regression parameter \pm standard error ( $p$ value*)

\begin{tabular}{|c|c|c|}
\hline & $\mathrm{AaDO}_{2}$ & Profusions $\dagger$ \\
\hline $\begin{array}{l}\text { Constant } \\
\text { Age (years) }\end{array}$ & $\begin{array}{l}-8.9 \\
0.43 \pm 0.07 \\
(<0.001)\end{array}$ & $\begin{array}{l}-3.9 \\
0.02 \\
\left(0.5 \frac{2}{2}\right)\end{array}$ \\
\hline Pack-years (current) & $\begin{array}{r}0.09 \pm 0.02 \\
(<0.001)\end{array}$ & $\begin{array}{l}0.01 \pm \frac{ \pm}{(0.06)} \\
0.01\end{array}$ \\
\hline Pack-years (ex-) & $\begin{array}{c}0.02 \pm 0.03 \\
(0.48)\end{array}$ & $\begin{array}{c}0.009 \pm 0.01 \\
(0.4 \overline{3})\end{array}$ \\
\hline $\begin{array}{l}\text { Cumulative exposure } \\
\text { (Alone in model } \ddagger)\end{array}$ & $\begin{array}{c}1.0 \pm 0.37 \\
(0.01) \\
0.53 \pm 0.29 \\
(0.07)\end{array}$ & $\begin{array}{l}0.09 \pm 0.16 \\
\left(0 \cdot 5 \frac{ \pm}{6}\right) \\
0 \cdot 10 \pm 0.13 \\
\left(0 \cdot 4 \frac{ \pm}{3}\right)\end{array}$ \\
\hline $\begin{array}{l}\text { Years worked } \\
\text { (Alone in model) }\end{array}$ & $\begin{array}{c}-0.21 \pm 0.10 \\
(0 . \overline{04}) \\
-0.04 \pm 0.08 \\
(0 . \overline{58})\end{array}$ & $\begin{array}{c}0.005 \pm 0.04 \\
(0.90) \\
0.02 \pm 0.03 \\
(0.57)\end{array}$ \\
\hline Adjusted $\mathrm{R}^{2}$ & 0.31 & naई \\
\hline
\end{tabular}

*From one df $\mathrm{F}$ test of $\mathrm{H}_{0}: \mathrm{b}=0$.

†From logistic model with dependent variable: any profusion of $0 / 1$ or greater yes/no (see text).

In a model with all the terms shown except the years worked term. $\S$ Not applicable to logistic models. were selected arbitrarily. The importance of the particular cut off points chosen for the three periods was investigated by testing exposure parameters for alternative sets of periods. The association of $\mathrm{AaDO}_{2}$ with exposures of the most recent past persisted when this period was redefined as the most recent five years (rather than ten years) and an association was found when just the two years was considered, although this latter effect was relatively unstable. When the remote period was redefined to begin 10 or 15 years before the survey (rather than 20 years), the strength of the associations between cumulative exposure in this period and FVC or FEV, was diminished.

Both $\mathrm{AaDO}_{2}$ and radiographic abnormalities were associated with exposures during the past 10 years. To investigate whether these changes are seen equally among those employed for more than and less than 10 years, or whether the effect of recent exposure is greater among those with longer employment, an interaction term for recent and long term exposure was added to the model as follows:

$$
\begin{gathered}
y=b_{0}+b_{1} \text { age }+b_{2} \text { current pack-years }+b_{3} \text { ex- } \\
\text { pack-years }+b_{4} C E_{1-10}+b_{5} \text { years } \\
\text { years } \left.{ }_{\geqslant 11}\right)
\end{gathered}
$$

Table 6 Models for three measures of pulmonary function with variables representing exposure at different times before

\begin{tabular}{|c|c|c|c|}
\hline & $F V C$ & $F E V_{1}$ & $M M E F$ \\
\hline $\begin{array}{c}\text { Exposure 0-10 } \\
\text { years before }\end{array}$ & $\begin{array}{r}46 \pm 29 \\
(0 \cdot 12)\end{array}$ & $13 \pm \frac{ \pm 25}{(0.60)}$ & $\begin{array}{r}-12 \pm 51 \\
(\overline{0} \cdot 82)\end{array}$ \\
\hline $\begin{array}{l}\text { Exposure 11-20 } \\
\text { years before }\end{array}$ & $\begin{array}{r}13 \pm 20 \\
(0.53)\end{array}$ & $\begin{array}{c}7.3 \pm 17 \\
(0.67)\end{array}$ & $\begin{array}{r}-13 \pm 35 \\
(0 \cdot 70)\end{array}$ \\
\hline $\begin{array}{l}\text { Exposure } \geqslant 21 \\
\text { years before }\end{array}$ & $\begin{array}{r}-47 \pm 17 \\
(0.005)\end{array}$ & $-33 \underset{(0.03)}{ \pm}$ & $\begin{array}{r}-15 \pm 30 \\
(0.63)\end{array}$ \\
\hline Adjusted $\mathbf{R}^{2}$ & 0.50 & 0.55 & 0.34 \\
\hline
\end{tabular}
health survey. Regression parameter* \pm standard error ( $p$ value $\dagger$ )

*Estimated from linear models of the form: $y=b_{0}+b_{1}$ age $+b_{2}$ height $+b_{3}$ current pack-years $+b_{4}$ ex-pack-years $+b_{5}$ exposure ${ }_{0} 10$ $+b_{6}$ exposure $1120+b_{7}$ exposure $\geqslant 21$ where $b_{5}, b_{6}, b_{7}$ are shown above.

†From one df $F$ test of $\mathrm{H}_{0}: b=0$. 
Table 7 Models for alveolar-arterial oxygen gradient $\left(\mathrm{AaDO}_{2}\right)$ and the profusion of small and irregular radiographic opacities, using variables representing exposure at different times before health survey. Regression

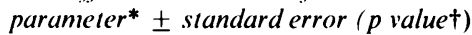

\begin{tabular}{|c|c|c|}
\hline & $A a D O_{2}$ & Profusions + \\
\hline Exposure $0-10$ years before & $1 \cdot 1 \pm 0.40$ & $0.32 \pm 0.18$ \\
\hline Exposure $11-20$ years before & $\begin{array}{c}-0 \cdot 12 \pm 0.28 \\
(0.66)\end{array}$ & $\begin{array}{c}0.006 \pm 0.12 \\
(0.96)\end{array}$ \\
\hline Exposure $\geqslant 21$ years before & $\begin{array}{c}-0.06 \pm 0.24 \\
(0.80)\end{array}$ & $\begin{array}{c}0.006 \pm 0.9 \\
(0.95)\end{array}$ \\
\hline Adjusted $\mathrm{R}^{2}$ & 0.31 & naş \\
\hline
\end{tabular}

*Estimated from linear models of the form: $y=b_{0}+b_{1}$ age $+b$, current pack-years $+b_{3}$ ex-pack-ycars $+b_{4}$ exposure $_{110}+b_{5}$ exposure $_{11} 21+b_{6}$ exposure $\geqslant 21$, where $b_{4}, b_{5}, b_{n}$ are shown above.

+ From one df $F$ test of $\mathrm{H}_{4}: b=0$.

†From logistic model with dependent variable: any profusion of $0 / 1$ or greater yes/no (see text).

$\$$ Not applicable to logistic models.

where years $\geqslant 11$ is a dummy variable coded 0 for years worked $<10$, and 1 otherwise. For radiographic abnormalities, there was no additional effect of longer term employment, either on the intercept or slope of the exposure response relation (table 8). For $\mathrm{AaDO}_{2}$, the model was more complex. Workers with more than 10 years tenure had a lower intercept than those with less tenure. The parameter estimate for the interaction term indicates a marginal difference in the slopes of the exposure response relation for those with short and long tenure $(p=0.08)$. These findings suggest that workers with more than 10 years in the plant had generally lower levels of $\mathrm{AaDO}_{2}$, after correcting for age and smoking differences.

To test for the possibility that exposures received at different intensities might have different magnitudes of effect, cumulative exposure was partitioned into two exposure parameters: intensity ${ }_{<25}$ and intensity ${ }_{\geq 25}{ }^{\circ}$ These two parameters represent the sum of all annual exposures that were above and below $25 \mu \mathrm{g} / \mathrm{m}^{3}$ respectively. Exposures partitioned by intensity in this way showed no clear association with any of the lung function measurements and this partitioning approach was not investigated further.

Because cumulative exposure data were transformed logarithmically in all models, the effect of alternative transformations of the cumulative exposure parameters partitioned by period was investigated. Similar patterns of associations among periods were observed using untransformed cumulative exposures, but the coefficients for the exposure parameters were less stable and the overall goodness of fit for the models (measured by adjusted $\mathbf{R}^{2}$ ) was poorer. When the exposure data were transformed by taking the square root or fourth root, the results were again qualitatively similar with tests for goodness of fit that were intermediate between the untransformed and logarithmic versions.

Finally, the data were restricted to the subset of the population with normal chest radiographs, so that an association between exposure to beryllium and decrements in pulmonary function could be assessed in a population with no cvidence that might suggest clinical beryllium disease. Again, the associations of $F V C$ and $F E V$, with exposures in the distant past were observed, and the point estimates, about -50 and $-30 \mathrm{ml}$ per $\ln \left(\mu \mathrm{g} / \mathrm{m}^{3}\right.$ - year $)$ of beryllium respectively, were similar to those for the full data set.

\section{Discussion}

SOURCES OF BIAS

An accurate retrospective estimate of exposure is difficult and some misclassification of true exposures doubtless occurred. ${ }^{6}$ The extent of this misclassification cannot be assessed, although such misclassification was random with respect to health state and therefore conservative.

Selection effects were perhaps a more serious source of potential bias. Exposure to beryllium in some operations was measured at levels above $100 \mu \mathrm{g} / \mathrm{m}^{3}$, a concentration which is reported to cause acute beryllium disease in man. ${ }^{6}$ In 1943 labour turnover in the plant approached $100 \%$ a year. ${ }^{.1}$ The present workers, and particularly the subgroup with many years of service, are therefore likely to be a "survivor" population. Assuming that workers who left work due to the acute effects of beryllium would have been at greater risk of developing more chronic effects had

Table 8 Models for alveolar-arterial oxygen gradient $\left(\mathrm{AaDO}_{2}\right)$ and the profusion of small and irregular radiographic opacities, allowing for interaction between exposure and duration of employment. Regression

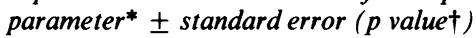

\begin{tabular}{|c|c|c|}
\hline & $\mathrm{AaDO}_{2}$ & Profusions \\
\hline Constant & $-9 \cdot 3 \pm 2.3$ & $-4 \cdot 1 \pm 1 \cdot 2$ \\
\hline Age (years) & $\begin{array}{r}0.44 \pm 0.06 \\
(<0.001)\end{array}$ & $\begin{array}{c}0.02 \pm 0.03 \\
(0.48)\end{array}$ \\
\hline Pack-years (current) & $0.09 \pm 0.02$ & $0.01 \pm 0.01$ \\
\hline Pack-years (ex) & $\begin{array}{c}0.02 \pm 0.03 \\
(0.57)\end{array}$ & $\begin{array}{c}0.01 \pm 0.01 \\
(0.52)\end{array}$ \\
\hline $\mathrm{CE}_{110}$ & $\begin{array}{c}0.53 \pm 0.51 \\
(0.30)\end{array}$ & $\begin{array}{c}0.19 \pm 0.29 \\
(0.51)\end{array}$ \\
\hline Years $\geqslant 11$ & $-5 \cdot 8 \pm 2 \cdot 2$ & $\begin{array}{c}-0 \cdot 36 \pm 1 \cdot 1 \\
(0 \cdot 74)\end{array}$ \\
\hline $\begin{array}{l}\text { Interaction of } \\
\mathrm{CE}_{110}{ }^{*} \text { years }\end{array}$ & $\begin{array}{c}1 \cdot 3 \pm 0.72 \\
(0 \cdot 08)\end{array}$ & $\begin{array}{c}0 \cdot 20 \pm 0 \cdot 36 \\
(0 \cdot 58)\end{array}$ \\
\hline
\end{tabular}

*Estimated from linear models of the form: $y=b_{0}+b_{1}$ age $+b_{2}$ current pack-years $+b_{3}$ ex-pack-years $+b_{4} C_{110}+b_{5}$ years $\geqslant 11+$ $b_{6}\left(C E_{1}{ }_{10}^{*}\right.$ years $\left.{ }_{311}\right)$. See text for descriptions of parameters.

+ From one df $F$ test of $H_{0}: b=0$. 
they remained exposed, then the bias would be conservative. The observation that workers with more than 10 years of tenure at the plant had lower-that is, "better"-values of $\mathrm{AaDO}_{2}$ on average than those with less tenure may be evidence for this survivor effect.

\section{LIMITATIONS OF MODELLING METHODS}

A search was made for alternative explanations of the observed exposure response associations. The associations of exposure in the distant past with decrements in FVC and FEV $_{1}$ and of exposure in the recent past with increases in $\mathrm{AaDO}_{2}$ were found to be fairly robust to changes in the form of the models used to estimate them. When modelling exposure response relation, the choice of scale for the exposure parameters has implications for the shape of the exposure response curves. Logarithmic transformation of exposure parameters implies a linear relation between exposure and response on a logarithmic scale. In this study the $\log$ models fit the data better than did other transformations of the exposure parameters but the differences were not great and the data lacked the statistical power to distinguish between the various models.

The linear models reported here may be thought of as predicting changes in the mean values of outcome variables as functions of the exposure parameters. It is difficult to say whether the observed exposure response associations are the result of exposure related effects confined to a small group of "susceptible" individuals or an association of constant magnitude for all. Such a distinction is best investigated by longitudinal studies of exposed individuals.

\section{INTERPRETATION OF RESULTS}

If cross sectional associations reported here can be interpreted causally and can be applied to the longitudinal experience of similarly exposed individuals they confirm that beryllium has both short and long term effects on lung function, as indicated by exposure related increases in $\mathrm{AaDO}_{2}$ and decrements in FVC and $\mathrm{FEV}_{1}$, respectively.

The models in tables 6 and 7 predict a loss of FVC and $\mathrm{FEV}_{1}$ proportional to exposures more than 20 years before the survey. A hypothetical worker assigned the median values on all covariates (age, height, pack-years, and exposures in more recent periods) would be expected to have the following decrements in function when compared with the same worker with no exposure 21 or more years before survey: a cumulative exposure of $100 \mu \mathrm{g} / \mathrm{m}^{3}$ - years would predict a decrement of $220 \mathrm{ml}$ in FVC and $150 \mathrm{ml}$ in $\mathrm{FEV}_{1}$; a cumulative exposure of $1000 \mu \mathrm{g} / \mathrm{m}^{3}$ -years would predict a decrement of $330 \mathrm{ml}$ in FVC and $220 \mathrm{ml}$ in $\mathrm{FEV}_{1}$. Twenty one per cent of the cohort received estimated cumulative exposures to beryllium of greater than $100 \mu \mathrm{g} / \mathrm{m}^{3}$ - years, and about $2 \%$ received cumulative exposures over $1000 \mu \mathrm{g} / \mathrm{m}^{3}$ - years in the relevant period.

An association between exposure to beryllium and FVC or FEV , has not been reported in epidemiological studies of beryllium workers. The present finding is important for several reasons. Firstly, decrements in FVC and FEV, were observed in workers who had no radiographic abnormalities, thus raising the possibility that radiographically diagnosed beryllium disease is not the only long term effect of exposure to beryllium.

A second important feature of the decrements in FVC and FEV, is that these losses in function were proportional to cumulative exposure. The existence of an immunological component to chronic beryllium disease has led to suggestions that the effects may not be dose related. ${ }^{12}$ Whether this is true for chronic beryllium disease (as traditionally defined) is not clear but our findings suggest that there may be subclinical decrements in function that progress with continuing exposure. The magnitudes of the observed associations between beryllium and decrements in FVC and FEV , were not great but our estimates are probably conservative and an underestimation of the true association could have resulted from several forms of bias (as described above). The strength of the present findings lies more in the observed patterns of association over time, and the persistence of these patterns through a number of alternative statistical models, than in the magnitudes of the predicted relations between exposure and response.

Previous studies of groups of beryllium workers failed to find an effect of beryllium exposure on either FVC or $\mathrm{FEV}_{1}{ }^{2-4}$ The studies by Sprince et al and Kanarek et al examined workers in another United States beryllium extraction plant that had been operating for only 15 years at the time of the first survey, ${ }^{23}$ Since exposure to beryllium in the preceding 15 years was not associated with decrements in pulmonary function in the present study, our findings are consistent with the earlier studies. Cotes et al followed up a small cohort in a British beryllium plant and found essentially no exposure related effects on lung function, ${ }^{4}$ but exposures were considerably lower than those estimated for workers in the present study. Thus an insufficient period of exposure or low intensities of exposure to beryllium may explain the negative findings in these other studies.

The association of exposure to beryllium with decrements in FEV , observed in our study suggests that beryllium may have an effect on airways. Both obstructive and restrictive defects in pulmonary function were reported by Andrews et al in a large series of patients with chronic beryllium disease. ${ }^{13}$ They also 
found subjects who had normal lung volumes and flows but reduced diffusing capacity, suggesting an impairment at the level of the alveolocapillary membrane. Available evidence from lung function studies thus indicates that beryllium can affect airways and lung parenchyma, so that predominantly "obstructive" or "restrictive" ventilatory patterns are expected; a mixed "obstructive-restrictive" pattern is also possible.

The $\mathrm{AaDO}_{2}$ was associated with exposures in the recent past. A worker with a cumulative exposure of 10 $\mu \mathrm{g} / \mathrm{m}^{3}$ - years in the 10 years before survey would be expected to have an $\mathrm{AaDO}_{2} 5 \mathrm{~mm} \mathrm{Hg}$ higher than the same worker without such exposure; at exposure levels of $100 \mu \mathrm{g} / \mathrm{m}^{3}$ - years in the past 10 years, the increase in $\mathrm{AaDO}_{2}$ would be $7 \mathrm{~mm} \mathrm{Hg}$. Kanarek et al and Sprince et al have reported an association between beryllium exposure and $\mathrm{AaDO}_{2}$ in another exposed population, ${ }^{23}$ and Stokinger found hypoxaemia in dogs with beryllium exposures below which any other lung function effects were observed. ${ }^{5}$ Sprince et al reported that $\mathrm{AaDO}_{2}$ improved after a substantial reduction in beryllium air levels. ${ }^{3}$ They hypothesised that there was an early, reversible component to beryllium disease manifested by an increased $\mathrm{AaDO}_{2}$ and mild interstitial infiltrates visible on chest radiograph. ${ }^{3}$ The observation that recent exposures to beryllium were associated with increased $\mathrm{AaDO}_{2}$, whereas longer term exposures were not, is consistent with a reversible defect at the level of the alveolocapillary membrane. Possibly the absence of an association between longer term (more than 10 years) exposure and $\mathrm{AaDO}_{2}$ is a result of selection bias. The observation that workers with more than 10 years of tenure have more normal values of $\mathrm{AaDO}_{2}$ on average than do workers more recently hired (table 8 ) suggests that a healthy worker effect may be operating.

Beryllium exposure was weakly associated with the profusion of small and irregular opacities on chest radiograph. The association appeared only with recent exposure (in the 10 years before survey). Most of the abnormalities were mild. Kanarek $e t$ al and Sprince $e t$ al also reported radiographic changes of mild interstitial infiltrates that appeared to resolve after reduction of beryllium exposures. ${ }^{23}$ Possibly the radiographic changes seen in the present study and by Kanarek and Sprince represent inflammatory changes that are potentially reversible.

Despite methodological weaknesses inherent in cross sectional studies, the present findings among workers exposed to beryllium indicate both short and long term effects on lung parenchyma and the airways. These changes are distinct from "classical" chronic beryllium disease. Longitudinal studies of exposed workers are needed to define further the subclinical effects of beryllium and to investigate whether a mild abnormality in $\mathrm{AaDO}_{2}$ predicts further lung function changes.
We thank Mr Richard Chamberlain, former director of the Environmental Medical Service, Massachusetts Institute of Technology, for invaluable help in interpreting industrial hygiene data, and the physicians, technicians, and secretaries of the pulmonary unit of the Massachusetts General Hospital for their help with field work and numerous other aspects of the study.

Supported in part by a grant to the Harvard School of Public Health from the Mobil Foundation and by grant R03-OHO1684 from the National Institute for Occupational Safety and Health. Dr Kriebel was supported by a training grant from the National Heart Lung and Blood Institute, No T32 HL 07118-09. Dr Sprince was supported in part by National Institute of Environmental Health Science grant RO1 ES03301.

Requests for reprints to: Dr David Kriebel, Occupational Health Program, Harvard School of Public Health, 665 Huntington Avenue, Boston, MA 02115 .

\section{References}

1 Cullen MR, Cherniack MG, Kominsky JR. Chronic beryllium disease in the United States. Seminars in Respiratory Medicine 1986;7:203-9.

2 Kanarek DJ, Wainer RA, Chamberlin RI, Weber AL, Kazemi H Respiratory illness in a population exposed to beryllium. Am Rev Respir Dis 1973;108:1295-1302.

3 Sprince NL, Kanarek DJ, Weber AL, Chamberlin RI, Kazemi H. Reversible respiratory disease in beryllium workers. $\mathrm{Am} \mathrm{Rev}$ Respir Dis 1978;117:1011-7.

4 Cotes JE, Gilson JC, McKerrow CB, Oldham PD. A long-term follow-up of workers exposed to beryllium. $\mathrm{Br} J$ Ind Med 1983;40:13-21.

5 Hall RH, Scott JK, Laskin S, Stroud CA, Stokinger HE. Acute toxicity of inhaled beryllium, III. Arch Ind Hyg Occup Med 1950;2:25-48.

6 Kriebel D, Sprince NL, Eisen EA, Greaves IA. Pulmonary function in beryllium workers: assessment of exposure. $\mathrm{Br} J$ Ind Med 1988;45:83-92.

7 Eisen EA, Oliver LC, Christiani DC, Robins JM, Wegman DH. Effects of spirometry standards in two occupational cohorts. Am Rev Respir Dis 1985;132:120-4.

8 International Labour Office. Guidelines for the use of ILO international classification of radiographs of pneumoconioses. Geneva: ILO, 1980.

9 West JB. Respiratory physiology. 2nd ed. Baltimore: Williams and Wilkins, 1979.

10 Dockery DW, Ware JM, Ferris BG, et al. Distribution of forced expiratory volume in one second and forced vital capacity in healthy, white, adult never-smokers in six US cities. Am Rev Respir Dis 1985;131:511-20.

11 Shilen J, Galloway AE, Mellor JF. Beryllium oxide from berylhealth hazards incident to extraction. Industrial Medicine 1944;13:464-9.

12 Eisenbud M, Lisson J. Epidemiological aspects of berylliuminduced nonmalignant lung disease: a 30-year update. J Occup Med 1983;25:196-202.

13 Andrews JL, Kazemi H, Hardy HL. Pattern of lung dysfunction in chronic beryllium disease. Am Rev Respir Dis 1969;100: 791-800. 